\title{
Delivering optimal care to the person with asthma: what are the key components and what do we mean by patient education?
}

\author{
M.R. Partridge
}

\begin{abstract}
Delivering optimal care to the person with asthma: what are the key components and what do we mean by patient education? M.R. Partridge. @ERS Journals Ltd 1995.

ABSTRACT: The new understanding of the pathogenesis of asthma has led to an increasing perception of the disease as a chronic condition, rather than one consisting of acute exacerbations. Health professionals need to help patients to accept this new understanding, and this involves a consideration of how best to deliver care and how best to enhance compliance.

Good communication is essential, and structured patient education has now been shown to be cost effective. All health professionals need to think how education may best be incorporated into their care. Such care will involve the development of a partnership between health professional and the patient and their loved ones, and the acquisition by patients of skills in self-management.

Several unknowns remain regarding who benefits more from group education as opposed to individual education, and some details of guided self-management. However, in the face of clear evidence of the benefits of patient education, these areas for further study should not delay the adoption of a strong commitment to education by all of those who care for those with asthma.

Eur Respir J., 1995, 8, 298-305.
\end{abstract}

\author{
Correspondence: M.R. Partridge \\ Whipps Cross Hospital \\ London E11 1NR \\ UK \\ Keywords: Asthma \\ compliance \\ education \\ organisation \\ self management
}

Received: July 201994

Accepted after revision November 23 1994
Asthma is a common condition for which we have available effective treatments. The more recent understanding of the pathogenesis of the condition has meant that over a relatively short period of time health professionals and patients have had to adapt, and accept that, for many, it is a chronic condition requiring regular treatment rather than being a series of isolated acute attacks. This alteration of perception of the disease means more than a change in frequency or type of our prescriptions. It involves a realization by health professionals that the services we provide for those with asthma may need to change, that our approach to the patient may need to alter, and that the patients response to our new understanding may not be predictable.

A few decades ago, respiratory physicians may have been in the forefront of a realization of the problems of compliance, for the successful treatment of tuberculosis involved organization and strategies which gave great prominence to that subject. More recently, fellow physicians who care for those with diabetes have led the way in an appreciation of the importance of patient education and the behavioural aspects of chronic disorders. Such considerations have only recently started to creep back into respiratory journals, especially over the latter part of the last decade [1]. Our peers have produced for us international [2-4] and national [5, 6] guidelines on the management of asthma, and in all of these the importance of "patient education" has been stressed. However, the words may mean different things to different people.

To consider this subject involves a realization that ideal care probably necessitates there being well-organized, well-educated health professionals working in an adequately funded system, who give the correct treatments to patients in such a way that they use them to maximum advantage to keep themselves well.

We therefore need to look briefly at health professional issues, at the organization of care, and at communication and compliance, as well as purely at the subjects of patient education and self-management.

Health professionals and the organization of care

Good care involves, as a minimum, a well-educated optimally organized health professional making the correct diagnosis, prescribing the correct treatment and offering continuity and follow-up. The older literature suggests that there may be delays in the making of the correct diagnosis, perhaps now as much in the elderly [7, 8] as in children [9], and audit has suggested that even amongst those with the more severe asthma only $50 \%$ are receiving the correct inhaled steroids $[10,11]$. 
Such undertreatment may be associated with unnecessary morbidity, or indeed mortality, but it also has significant economic implications. A crude analysis by BLAINEY et al. [12] looked at the cost of in-patient treatment if optimal prior management of patients is not achieved. In this analysis, patients were reviewed to assess whether the admission could have been prevented. Seventy three percent (55 of 75) of admissions were so classified, and at 1990/1991 prices this level of "mismanagement" equated to an annual cost of preventable asthma admissions of $£ 44,860$ per 100,000 catchment population.

The guidelines that have been published may be a good basis for the education of health professionals, but only if they lead to an appropriate change in behaviour. In a review of 59 published evaluations of clinical guidelines in all fields, all but four of the 59 studies detected significant improvement in the process of care after the introduction of guidelines, and all but two of the 11 studies that assessed the outcome of care, reported significant improvement [13]. The situation regarding the impact of asthma guidelines is unclear, but benefit is most likely to occur when guidelines are adapted for use within one department or district [14, 15].

It is also important to look at the way in which health professionals organize their care for those with asthma. One study suggested that if in-patient care of those with acute asthma was by generalists rather than specialists, the patient was 10 times more likely to be readmitted in the subsequent year [16]. Another audit showed similar results, with $14 \%$ of those cared for by general physicians being readmitted within 3 months compared with $6 \%$ whose first admission was under the care of a chest physician [17]. It is unclear why specialist care is associated with a better outcome, but in both studies follow-up of patients was more likely if they were admitted under a specialist. It is likely that the specialist is more aware of the need for continued supervision and support, and the need for the development of a partnership for care.

Care both by generalists and specialists can improve, and the gap between the two was shown to have narrowed between 1978 and 1985 in one study [18]. Similar improvements in care have been demonstrated by serial audit in General Practice [19]. Another large study also showed significant improvements in the in-patient care of asthma over a decade [20]. These audits have largely involved the management of acute severe asthma, and yet the majority of those with asthma do not require admission, and the organization of community care for them is the important consideration. How this is done will vary from country to country, and will vary according to types of health-care systems and to availability of health professionals. A key feature, however, may be the ability to provide regular supervision for what is now agreed to be a long-term condition. This may involve the organization of special "asthma clinics", whereby patients are regularly recalled and reviewed. Such clinics may be entirely doctor run or may use other health professionals, such as nurses.

There are few controlled studies looking at the efficacy of such structured care alone and those that are available are conflicting. One for children (run by general practitioners) showed only minimal benefit [21], whereas other clinics have appeared to show benefit in terms of patients self-management ability and reduction in school absenteeism. Another such study in General Practice before and after introduction of a nurse run asthma clinic showed improved morbidity, reduced stigma and increased confidence in those attending the clinic [22]. What needs to be defined in such studies is what was involved in the intervention (closer supervision, more treatment, or training in self-management), and we need to elucidate which of the interventions is the most useful. Furthermore, we need to be certain that those who attend for regular review actually represent those "at risk", and that all ages and all socioeconomic groups are represented. If work is to be shared with other health professionals, we need to be sure that such colleagues have had adequate training for the task. Deficiencies in nurse training have been identified in one large survey, with $22 \%$ of nurses who were running clinics by themselves not having had formal evaluable training [23].

If health services are optimally organized and if the health professional writes the correct prescription, how likely is it to be taken, and how good are we at communicating with our patients?

\section{Compliance and communication}

The term compliance is not used in a pejorative sense, and it remains a perfectly acceptable term to define albeit only one narrow aspect of patient behaviour. Studies in many chronic conditions, whether tuberculosis, glaucoma or hypertension, have previously shown noncompliance rates of around $50 \%$, and similar results have been shown in studies both in children and in adults with asthma. One review of adults suggested a range of compliance of 20-80\% [24]. The accuracy of such data varies with the method of assessment, whether by diary card, verbal or written questionnaire, drug assay, pill counting, aerosol weighing, assessment of outcome, or by electronic means, and compliance is most unlikely to be a static phenomenon.

In a study of compliance with a three times daily placebo/anticholinergic agent trial in chronic obstructive pulmonary disease (COPD), assessment by use of electronic microprocessor attached to a metered-dose inhaler (the nebulizer chronolog) showed that diary cards and cannister weighing overestimated compliance, with the microprocessor showing that only $15 \%$ of patients actually used the inhaler an average of 2.5 or more times per day [25]. The implications of this study may be considerable in terms of future design of clinical trials, but from a clinical viewpoint, what are the factors involved in such noncompliance?

Simple problems with inhaler devices and problems with complicated four times daily regimens or with misunderstanding of instructions are commonplace but obvious [26, 27]. Good communication between the health professional and patient is vital in ensuring 
compliance, and this involves patients having plenty of opportunity to express their fears and concerns and to ask their questions [28, 29]. It is important to explore the patient's concept of the disease and its treatment, and to motivate patients to request the information which they want, so that they may make a correct evaluation of the risks/benefits of taking therapy. However, it is likely that too often we fail to perceive how the patient feels about having their condition and its effect upon their relationships with others, and we fail to acknowledge that each brings to a standard disease a very nonstandard personality, a differing psychological profile and different previous experiences.

In one survey, $39 \%$ of those with asthma felt that having asthma had a great deal, or quite a lot, of influence on their everyday life, with a further $35 \%$ thinking that it had a moderate amount of influence [30]. Nocon and Воотн [31] have similarly shown that having asthma can influence relationships and induce feelings of anger, guilt and worry. Others have studied patients' attitudes to medication and have confirmed the dislike of a significant proportion of patients for the regular use of any medication [32]. Dislike of steroid medication was no greater than for regular medication of any sort, but it is likely that dislike is related in significant part to concern regarding side-effects and feelings of dependence. Questions about side-effects of medication have been reported as one of the commonest reasons for calls to a National Asthma Telephone Helpline [33]. Others have suggested that noncompliance is associated with depression [34], and this may be common, for another study reported $32 \%$ of those with asthma as being depressed, $38 \%$ being angry, and $20 \%$ feeling different to other people [35].

Compliance (or otherwise) with medication is, thus, the end result of a complex interaction involving advice and information and psychosocial behaviour. The first aim is for the health professional to be aware of the size of the problem. We need to elicit noncompliance, and then elucidate the factors involved and try to develop strategies which may lead to improvement. Simple questions, such as "So that we may plan your future treatment, can you tell me how often you remember to take the inhaler?" acknowledge the likelihood of noncompliance, and the factors likely to be involved may then be explored. Unless hidden fears are elicited, they act as a barrier to further educational efforts [1]. We should, thus, be asking patients "How do you feel about having asthma?" and "What do you want from me?". Health professionals are aware of patients fears regarding side-effects, but rarely initiate a discussion on the subject. It is essential that the subject is regularly on the agenda, and fears regarding side-effects may be elicited by questions, such as "How do you feel about taking your treatment?" or "Some people think steroids are harmful, what do you think?" [36]. The patients can then be given an opportunity to express their concerns and be provided with a balanced view on which to base their future decision-making.

Audit suggests that we may not be communicating well at present. A 1993 UK National Asthma Campaign survey of 1,631 people with asthma showed that at the time of diagnosis, only $22 \%$ reported having had a good discussion with their doctor or nurse, and only $9 \%$ felt that they were given plenty of information [37]. Giving information improves knowledge [38], but knowledge does not necessarily increase compliance [39]. A complex interplay of numerous factors needs to be disentangled, and the individual components evaluated to try and produce a list of "best buys", which may lead to improved outcomes.

Communication involves a circular model in which the three components are the sender, the message and the recipient. One study suggested that the doctor was the preferred provider of information about asthma [40]. In some countries, physiotherapists or trained educators are also used, whilst in other countries nurses are increasingly prime members of the team. The efficacy of each needs evaluation, and as simple providers of information, all may not be equal. A study of 100 moderate to severe asthmatics recruited from general practice showed that only $25 \%$ of patients who received an initial explanation from a nurse totally understood the explanation, compared to $44 \%$ who received this from a general practitioner, and $46 \%$ from a hospital consultant [39]. Irrespective of who gives the verbal message, this must be similar, for nothing confuses patients more than to appear to be getting conflicting advice, and the use of guidelines by all health professionals may correct this situation.

Much that is said to the patient is quickly forgotten and it, therefore, needs to be repeated on more than one occasion, and verbal advice needs to be reinforced by other routes. Written information booklets are the commonest method. A UK National Asthma Campaign survey of 1,400 health professionals working in primary care in 1993 produced 699 responses [37]. Ninety two percent said that asthma was a condition for which they gave their patients booklets/leaflets, and this condition was a commoner reason to do so than heart disease $(84 \%)$, diabetes $(80 \%)$, cancer $(33 \%)$ or epilepsy $(17 \%)$. Nurses were slightly more likely to give such written material than doctors, but another survey of health visitors has shown that use varies considerably from one to another, and is influenced by their personal beliefs about appropriateness and by availability [41].

Leaflets may be less popular with patients than, for example, videotapes [40], and videotapes are a particularly good method of reinforcing verbal messages for those with poor literacy skills, and very good for skills training, such as in the use of an inhaler [42]. Computer-assisted reinforcement of verbal instruction has also been shown to be very effective in a controlled trial looking at methods of enhancing compliance with allergen avoidance measures [43]. It is also possible that written information booklets may be less effective in the transfer of knowledge than audiotapes [44], but ease of use, cost and availability means that leaflets/booklets will remain the commonest method of augmenting verbal advice. However, although health professionals may say that asthma is a condition for which they commonly use booklets they are not frequently received by patients. 
Table 1. - What do patients want to know about prescribed drugs

When and how to take medicine

Unwanted effects and what to do about them

Precautions (such as possible effects on driving)

Problems with alcohol or other drugs

The name of the medicine

The purposes of treatment

What to do if a dose is missed

(From the study by George [48]).

In the UK National Asthma Campaign survey of 1,631 people with asthma [37], 39\% had received booklets and $4 \%$ had the opportunity to watch videotapes. Only $27 \%$ had received written advice about their personal medication. This latter point is important, because whilst booklets alone do not necessarily alter behaviour [45], some form of personalization of written advice can have a beneficial outcome. In one study (not of asthma), the use of personalized computer-generated information about an individuals drug regimen was shown to improve both patient recall about the regimen and compliance [46]. Written instructions have also clearly been shown to improve compliance with a series of management changes in paediatric asthma [47]. The information patients require about medication has been evaluated, and GEORGE [48] has reported that patients regard seven pieces of information as being particularly important (listed in table 1). Using word processors to personalize information booklets, which were sent through the post to patients four times over a 12 month period, has also been demonstrated to reduce hospitalization [49].

It is, thus, vital that we recognize the challenges and the importance of good communication. We must enhance the quality of the sender, whether respiratory physician or primary care physician, and reinforce our verbal messages with high quality materials. However, above all is the realization that we must reduce the differences between what we believe the patient "needs" to know, and recognize that that is not always the same as what the patient "wants" to know.

How do we extend these strategies?

\section{Patient education and self-management}

In the preceding sections we have covered issues such as health professional organization and use, some of the barriers that there may be to our educational process, and have started an initial explanation of the sort of information patients may need or wish to receive. The emphasis on the circular model of sender, message and recipient has emphasized that this is a two-way process, and the patient needs to be motivated to access the circle as and when, and for as long as, he/she feels the need. It is also necessary to involve the patients' loved ones in this process, and it is likely that we underestimate the potential of their influence. One study of 397 co-habitees suggested that $29 \%$ of co-habitees always, or usually, made sure that the person with whom they lived took their medication for asthma [30].
The International Consensus Report on the Diagnosis and Treatment of Asthma [2] describes asthma management as having six interrelated parts, of which the first is "to educate patients to develop a partnership in asthma management". The aim of patient education is further defined as "a continual process designed to provide the asthma patient and the patient's family with suitable information and training, so that the patient can keep well and adjust treatment according to a medication plan developed with the clinician".

The key components are, thus, the development of a partnership, with a sharing of information and a full discussion by the patient of their expectations of both asthma and its treatment. It is important that the patient realizes their responsibilities towards the management of their condition.

Such care involves a continual revision and reinforcement of shared messages, and it is vital that we do not overload the patient with information, and that it is given in a graded fashion and usually in response to what the patient feels they want to know, as much as what the health professional thinks they need to know. However, it is likely that the basis of education will involve an understanding of the diagnosis, the difference between relieving and preventative therapies, and training in the use of inhaler devices. A key part of training involves prevention, both by helping the patient to identify factors that may worsen their asthma, and prevention by means of adjustment of treatment to avoid exacerbations. The goal for many is, thus, the acquisition of the skills of self-management. The rationale behind this is that "not feeling in control" and "fear of attack" are unpleasant sensations, and are often a powerful disincentive to compliance. It is, thus, thought that if patient education works it does so by improving the patients understanding of asthma and its treatment; and, thereby, increasing their confidence and their satisfaction with treatment, so that they are motivated to take greater control of their own condition. This, hopefully, leading to improved compliance and to a reduction in morbidity.

What is the evidence that such patient education and self-management actually works, and is it cost effective?

Initial studies of the giving of information alone showed improvements in knowledge but no significant changes in patient behaviour or outcome [44, 45]. Other early studies showed that by targeting frequent emergency room attenders or those admitted to hospital [50, 51], it was possible to reduce subsequent medical needs or improve quality of life. In some studies it was difficult to separate the benefit of the educational intervention from those of more regular review and more rational therapy. Subsequently, there have been several further controlled and uncontrolled studies both in children and adults.

TAGGART et al. [52] devised a programme for staff nurses to use with 6-12 year old children admitted to hospital. The children were given written materials and also shown videotapes played on the hospital television network, and each lesson was introduced by a nurse, who later went over the materials with the child. 
One of the key features of the programme was that it involved and utilized the staff already caring for the hospitalized child. There was no control group, but evaluation of the benefits involved each child acting as their own control in a pre/postprogramme principle; all had had at least one emergency hospital visit in the 6 months prior to exposure to the programme. Parents were questioned preprogramme and by telephone 3 months later, and the child undertook a knowledge assessment. Results showed improvements in the childrens' knowledge and in their feelings of control, and parents reported increased use of self-management techniques at follow-up. With the proviso that there was no control group, there was an apparent reduction in emergency room use after the educational intervention.

In another before and after trial, over 130 adults undertook a 5 day in-patient treatment and education programme, led by a trained nurse educator. Over a 12 month follow-up period, attacks were reduced, and there was a significant reduction in rehospitalization rates after the intervention compared to before [53]. A similarsized, controlled study followed up adults with asthma who had had a 30 min individual educational session, followed by a 60 min group session and two follow-up reinforcing phone calls. At 12 months post-intervention there were significant improvements in inhaler technique and in reported compliance (with some assay validation) [54].

In another controlled study in adults who had attended an emergency room with asthma, those who were offered three nurse run educational sessions (stressing methods of control, prevention of asthma, and emphasizing the use and importance of medicines) $(n=119)$, had significantly fewer repeat visits to the emergency room in the subsequent 12 months than a similar-sized control group. There was a suggestion in this study that the effect of the intervention diminished with time [55].

Longer term evaluation is available in a study from WILSON et al. [56], who also compared the benefits of individual with group education. Three hundred and twenty three adults, aged 18-50 yrs, with moderate to severe asthma were assigned to either group education, individual education, use of an 80 page self-use workbook, or no supplementary education. Both active educational interventions were conducted by a nurse educator and involved learning about objective and subjective monitoring, medication, and self-management. The number of educational interventions was individualized according to patient need, and in the group intervention there were four 90 minute sessions at weekly intervals. In both of the educational groups, there was a significant improvement in a patient rated "bother from asthma index" at one year after intervention, and significant improvement in inhaler techniques and in preventative methods of environmental control. Interestingly, the technical and environment control parameters had improved at 5 months and were maintained at one year, but the "bother index" had not improved significantly until 12 months had passed, suggesting that false negative results may occur with some outcome measures if follow-up after intervention is not sufficiently prolonged.
In this study, slightly greater benefit was achieved from the easier to administer group education, than from the individualized education.

Yoon et al. [57] have looked at simplifying the intervention. In a controlled trial of 16-65 year olds who had been admitted with acute asthma, a 3 hour group education programme, involving lectures, videotapes, individual skills-training and administration of a treatment plan, combined with a session to dispel misconceptions, was evaluated by 10 month follow-up by means of selfadministered questionnaires and measurement of peak flow and spirometry. In the intervention group, there was no significant improvement in home-recorded peak flows in the week prior to 10 month follow-up or in spirometry, but there was a decrease in admission rates and attendances at accident and emergency departments. Questionnaires also revealed a significant improvement in knowledge and in behaviour likely to be adopted in the event of worsening asthma.

A key proviso to all of these studies is that often large numbers of subjects had to be approached to obtain sufficient for study, and unwillingness to participate may be common and has been studied and characterized [58]. This suggests that every opportunity should be taken for opportunist education, for example, whilst hospitalized and whilst in emergency rooms, for although this may not be the best time to educate patients it may be the only opportunity available. Even the most ill, who may have most to gain, may not return for subsequent out-patient educational programmes [58], even when they initially agree to do so [59].

Several studies $[54,55]$ have attempted to cost the benefits of such educational programmes, with positive results, and even studies involving elective in-patient education have demonstrated cost-effectiveness in terms of subsequent savings [60].

Most of these studies have incorporated a basic premise that patients should take greater control of their own condition, and the interventions are, thus, designed to enhance self-management. Whilst this process includes issues such as environmental control, most emphasis is on changes the patient may make in therapy. In adults, most such plans are based on a combination of subjective and objective monitoring, with the dependency upon peak flows being justified by studies suggesting that significant numbers of those with asthma have a poor correlation between subjective perception of severity and objective monitoring [61-63]. In children, the situation is less clear, but even when the child can undertake peak flow monitoring, some suggest that serial peak flow monitoring may be efficacious [64], whilst others suggest that it may be misleading [65]. However, parents clearly value such objective clarification of the severity of their child's asthma [66].

Recent Japanese work [67] has suggested that some adults with near fatal attacks of asthma may have a diminished perception of breathlessness, and such patients clearly need to undergo objective monitoring of their condition.

When self-management plans are based on peak flow, the plan requires an optimal peak flow to be defined 
for the individual patient, and this is determined either from past records or from a period of maximal treatment. The International Consensus Report [2] suggests that peak flows of $80-100 \%$ of the individual best represents a satisfactory state, and routine treatment should be continued. Falls to $50-80 \%$ of personal best should lead to a change in treatment, which may include taking extra doses of bronchodilators, increasing anti-inflammatory treatment, and starting a course of steroid tablets. Peak flow falls to below $50 \%$ should lead to the patient taking urgent self-medication and seeking medical attention in a way previously determined for that individual.

The British Guidelines [6] do not delineate the level at which intervention should be instituted, recognizing that plans should be tailored for the individual patient, but the British Guidelines do allude to the possibility of a further step or zone - that of doubling the dose of inhaled steroids. This is often suggested as a step to be taken at the first sign of a cold, and this may be logical in view of recent studies showing the frequency with which attacks are associated with viral infections [68]. There has also been a recent suggestion that such increases of inhaled steroids may be effective [64], despite this having been noted as an area of uncertainty in the guidelines [6].

Issuing such 3-4 step self-management plans, whether on preprinted sheets or on credit card sized cards, has been evaluated in several trials [64, 69-71], with positive results. Another study suggests that it is those with the more severe asthma who are most likely to benefit [72].

Further research is needed to better define just who needs simple personalized advice about their treatment and about signs that suggest worsening asthma, and who needs detailed 3-4 step plans, and whether in all adults or in children these should be based on symptoms or on peak flow or both.

\section{Conclusions}

In conclusion, the audit evidence of improved outcomes with specialist care would suggest that well-educated health professionals are an essential component in the delivery of optimal care. Good communication between patients and health professionals is an essential prerequisite for good compliance. Patient education (and the acquisition of skills of self-management) is associated with improved outcomes and is cost effective. What is not known is whether limited resources should be best directed towards enhanced health professional training, towards the acquisition by them of skills in communication, directed towards patient education, or a combination of all. Patient education may be given as part of routine consultations or be delivered by trained educators in groups or individually. It is not yet clear who benefits most from which method of delivering patient education. Programmes should be as simple as possible, and may need to be delivered opportunistically to ensure that those at greatest need avail themselves of the benefits. Special measures may need to be instituted for certain risk groups, and we need to better delineate who needs what sort of detailed self-management plan.

However, awaiting such refinements of our knowledge is not an excuse for delay, and all of those who care for people with asthma need to look now at the services that they provide to ensure that these clearly demonstrated benefits of good communication and patient education are available to their patients. All patients need to understand the need for a partnership of care and to have adequate opportunities to express their fears and concerns. Verbal advice should be reinforced on repeated occasions and by the use of leaflets and video or audio tapes. Every patient or parent should have written advice about their particular medication regimen and clear instructions as to the signs that suggest worsening asthma, and what to do under those circumstances. All will require regular supervision and review, and for some the benefits of support within a group educational programme will have advantages.

\section{References}

1. Evans D. To help patients control asthma the clinician must be a good listener and teacher. Thorax 1993; 48: 685-687.

2. National Heart Lung \& Blood Institute, National Institutes of Health. International Consensus Report on diagnosis and management of asthma. Eur Respir J 1992; 5: 601641.

3. Warner JO, Gotz M, Landau LI, et al. Management of asthma: a consensus statement. Arch Dis Child 1989; 64: 1065-1079.

4. Warner JO, Gotz M, Landau LI, et al. Asthma: a followup statement from an international consensus group. Arch Dis Child 1992; 67: 240-248.

5. Hargreave FE, Dolovich J, Newhouse MT. The assessment and treatment of asthma: a conference report. J Allergy Clin Immunol 1990; 85: 1098-1111.

6. British Thoracic Society, British Paediatric Association, Royal College of Physicians of London, The Kings Fund Centre, The National Asthma Campaign, et al. Guidelines on the management of asthma. Thorax 1993; 48: S1-S24; and (summary charts), Br Med J 1993; 306: 776-782.

7. Banerjee DE, Lee GS, Malik SR, Daly S. Underdiagnosis of asthma in the elderly. Br J Dis Chest 1987; 81: 2329.

8. Holgate ST, Dow L. Airways disease in the elderly: an easy-to-miss diagnosis. J Respir Dis 1988; 9: 14-22.

9. Speight ANP, Lee DA, Hey EN. Underdiagnosis and undertreatment of asthma in childhood. Br Med J 1988; 286: 1253-1256.

10. Gellert AR, Gellert SL, Iliffe SR. Prevalence and management of asthma in a London inner city general practice. Br J Gen Pract 1990; 40(334): 197-201.

11. Horn CR, Cochrane GM. Management of asthma in general practice. Respir Med 1989; 83: 67-70.

12. Blainey AD, Beale A, Lomas D, Partridge MR. The cost of acute asthma. How much is preventable? Health Trends 1991; 22: 151-153.

13. Grimshaw JM, Russel IT. Effect of clinical guidelines in medical practice: a systematic review of rigorous evaluation. Lancet 1993; 342: 17-22. 
14. Town L, Kwong T, Holst P, Beasley R. Use of a management plan for treating asthma in an emergency department. Thorax 1990; 45: 702-706.

15. Lim KL, Harrison BDW. A criterion based audit of inpatient asthma care. J Roy Coll Phys 1992; 26: 71-75.

16. Bucknall CE, Robertson C, Moran F, Stevenson RD. Differences in hospital asthma management. Lancet 1988; i: 748-750.

17. Bell D, Layton AJ, Gabbay J. Use of a guideline based questionnaire to audit hospital care of acute asthma. $\mathrm{Br}$ Med J 1991; 302: 1440-1443.

18. Baldwin DR, Ormerod LP, Mackay AD, Stableforth DE. Changes in hospital management of acute severe asthma by thoracic and general physicians in Birmingham and Manchester during 1978 and 1985. Thorax 1990; 45: 130-134.

19. Barritt PL, Staples EB. Measuring success in asthma care: a repeat audit. Br J Gen Pract 1991; 41: 232236.

20. Bucknall CE, Robertson C, Norman F, Stephenson RD. Improving management of asthma; closing the loop or progressing along the audit spiral. Quality in Health Care 1992; 1: 15-20.

21. Usherwood TP, Barber JH. Audit of process and outcome in a mini clinic for children with asthma. Family Practice 1988; 5: 289-293.

22. Charlton I, Charlton G, Broomfield J, Campbell M. An evaluation of a nurse run asthma clinic in general practice using an attitudes and morbidity questionnaire. Family Practice 1992; 9: 154-160.

23. Barnes G, Partridge MR. Community asthma clinics. Quality in Health Care 1994; 3: 133-136.

24. Cochrane GM. Therapeutic compliance in asthma: its magnitude and implications. Eur Respir J 1992; 5: 122124.

25. Rand CS, Wise RA, Nide S, et al. Metered-dose inhaler adherence in a clinical trial. Am Rev Respir Dis 1992; 146: 1559-1564.

26. Crompton GK. Problems patients have using pressurised aerosol inhalers. Eur J Respir Dis 1982; 63 (Suppl. 119): 101-104.

27. Hilton S. An audit of inhaler techniques amongst asthma patients of 34 general practitioners. Br J Gen Pract 1990; 40: 505-506.

28. Korsch BM, Negrette VF. Doctor patient communication. Sci Am 1972; 227: 66-72.

29. Ley P. Towards better doctor-patient communications. Contributions from social and experimental psychology. In: Bennett AF, ed. Communications in Medicine. London, Oxford University Press, for the Nuffield Provincial Hospital Trust.

30. Applied Research and Communications Ltd. The Life Quality of Asthmatics. Uxbridge, Middx. Allen \& Hanburys Ltd, 1990.

31. Nocon A, Booth T. The social impact of asthma. Family Practice 1990; 8: 37-41.

32. Osman LM, Russell IT, Friend JA, Legge JS, Douglas JG. Predicting patient attitudes to asthma medication. Thorax 1993; 48: 827-830.

33. Crone S, Partridge MR, McLean F. Launching a national helpline. Health Visitor 1993; 66: 94-96.

34. Bosley CM, Fosbury JA, Cochrane GM. Psychological factors associated with poor patient compliance with inhaled treatment in asthma. Am J Respir Crit Care Med 1994; 149: A248.

35. Sibbald B. Patient self-care in acute asthma. Thorax 1989; 44: 97-101.
36. Partridge MR. Self-care plans for asthmatics. Practitioner 1991; 235: 715-721.

37. Partridge MR. Asthma: lessons from patient education. Patient Ed Counselling 1995; (In press).

38. Rubinfield AR, Dunt DR, McLure S. Do patients understand asthma? a community survey of asthma knowledge. Med J Aust 1988; 149: 526-530.

39. Tettersell MJ. Asthma patients knowledge in relation to compliance with drug therapy. J Advanced Nursing 1993; 18: 103-113.

40. Partridge MR. Asthma education: more reading or more viewing? J Roy Soc Med 1986; 79: 326-328.

41. Dixon M, Johnson R. Health visitors use of health educational material. Health Visitor 1994; 67: 167-168.

42. Mulloy EMT, Albazzar MK, Warley ARH, Harvey JE. Video education for patients who use inhalers. Thorax 1987; 42: 719-720.

43. Huss K, Salerno M, Huss RW. Computer-assisted reinforcement of instruction; effects on adherence in adult atopic asthmatics. Res Nurs Health 1991; 14: 259267.

44. Jenkinson D, Davidson J, Jones S, Hawtin P. Comparison of effects of a self-management booklet and audiocassette for patients with asthma. Br Med $J$ 1988; 297 : 267-270.

45. Hilton S, Sibbald B, Anderson HR, Freeling P. Controlled evaluation of the effects of patient education on asthma morbidity in general practice. Lancet 1986; i: 26-29.

46. Raynor DK, Booth TG, Blenkinsopp A. Effect of computergenerated reminder charts on patients compliance with drug regimens. $\mathrm{Br}$ Med $J$ 1993; 306: 1158-1161.

47. Pedersen S. Ensuring compliance in children. Eur Respir J 1992; 5: 143-145.

48. George CF. What do patients need to know about prescribed drugs. Prescribers $J$ 1994; 34: 7-11.

49. Osman L, Abdalla MI, Beattie JAC, et al. Reducing hospital admissions through computer-supported education for asthma patients. Br Med J 1994; 308: 568571.

50. Mayo PH, Richman J, Harris HW. Results of a program to reduce admissions for adult asthma. Ann Intern Med 1990; 112: 864-871.

51. Sandergaard B, Davidson F, Kirkeby B, Rasmussen M, Hey H. The economics of an intensive education programme for asthmatic patients: a prospective controlled trial. Pharmacoeconomics 1992; i: 207-212.

52. Taggart VS, Zuckerman AC, Sly RM, et al. You can control asthma: evaluation of an asthma education program for hospitalised inner city children. Patient Ed Counselling 1991; Vol. 17: 35-47.

53. Mulhauser I, Richter B, Kraut D, Weskk G, Worth H, Berger M. Evaluation of a structured treatment and teaching programme on asthma. J Intern Med 1991; 230: 157-164.

54. Windsor RA, Bailey WC, Richards JM, Manzella B, Soong SJ, Brooks M. Evaluation of the efficacy and cost-effectiveness of health education methods to increase medication adherence amongst adults with asthma. Am J Pub Health 1990; 80: 1519-1521.

55. Bolton MB, Tilley BC, Kuder J, Reeves T, Schultz LR. The cost and effectiveness of an education program for adults who have asthma. J Gen Intern Med 1991; 6: 401-407.

56. Wilson SR, Scamagas P, German DF, et al. A controlled trial of two forms of self-management education for adults with asthma. Am J Med 1993; 94: 564-576.

57. Yoon R, McKenzie DK, Bauman A, Miles DA. Controlled 
trial evaluation of an asthma education programme for adults. Thorax 1993; 48: 1110-1116.

58. Yoon R, McKenzie DK, Miles DA, Bauman A. Characteristics of attenders and nonattenders at an asthma education programme. Thorax 1991; 46: 886-890.

59. Turner MO, Crump S, Contrecas GR, Fitzgerald JM. The challenge of delivering asthma education to a high risk group. Am J Respir Crit Care Med 1994; 149: A251.

60. Trautner C, Richter B, Berger M. Cost-effectiveness of a structured treatment and teaching programme on asthma. Eur Respir J 1993; 6: 1485-1491.

61. Rubinfield AR, Pain MCF. The perception of asthma. Lancet 1976; i: 882-884.

62. Boner AL, De-Stafan G, Piacentini GL, et al. Perception of bronchoconstriction in chronic asthma. J Asthma 1992; 29: 323-330.

63. Kendrick AH, Higgs CMB, Whitfield MJ, Laszlu G. Accuracy of perception of severity of asthma: patients treated in general practice. Br Med $J$ 1993; 307: 422424.

64. Charton I, Antoniou AG, Atkinson J, et al. Asthma at the interface: bridging the gap between general practice and a district general hospital. Arch Dis Child 1994; 70: 313-318.

65. Sly PD, Cahill P, Willet K, Burton P. Accuracy of mini peak flow meters in indicating changes in lung function in children with asthma. $B r$ Med $J$ 1994; 308: 572-574.

66. Lloyd BW, Ali MH. How useful do parents find home peak flow monitoring for children with asthma. $\mathrm{Br} \mathrm{Med}$ J 1992; 305: 1128-1129.

67. Kikuchi Y, Okabe S, Tamura G, et al. Chemo-sensitivity and perception of dyspnoea in patients with a history of near fatal asthma. N Engl J Med 1994; 330: 13291334

68. Nicholson KG, Kent J, Ireland DC. Respiratory viruses and exacerbations of asthma in adults. Br Med J 1993; 307: 982-986.

69. Beasley R, D'Souze W, Tekaru H. Trial of an asthma action plan in the Maori community of the Wairarapa. NZ Med J 1993; 106: 336-338.

70. Charlton I, Charlton G, Broomfield J, Mullee MA. Evaluation of peak flow and symptoms only self-management plans for control of asthma in general practice. Br Med J 1990; 301: 1355-1359.

71. Beasley R, Cushley M, Holgate ST. A self-management plan in the treatment of adult asthma. Thorax 1989; 44: 200-204.

72. Grampian Asthma Study of Integrated Care (Grassic): effectiveness of routine self-monitoring of peak flow in patients with asthma. Br Med J 1994; 308: 564-568. 